\title{
Improving access to selective dorsal rhizotomy for children with cerebral palsy
}

\author{
Benjamin Davidson MD, Darcy Fehlings MD, Golda Milo-Manson MD, George M. Ibrahim MD PhD
}

Cite as: CMAJ 2019 November 4;191:E1205-6. doi: 10.1503/cmaj.191065

A recent national policy decision in the United Kingdom to fund selective dorsal rhizotomy (SDR) for cerebral palsy has focused attention on this procedure, which remains underused in Canada. The UK decision was based on a recently published commissioned multicentre prospective open-label trial of SDR that showed the procedure to be associated with significant increases in gross motor function and quality of life for children with moderate cerebral palsy. ${ }^{1}$ In Canada, access to SDR for children with this disorder remains variable and limited, with many provinces not performing this procedure and others capping funding or restricting indications. Many Canadian families have travelled south of the border at their own expense and risk to access SDR, which has attracted considerable media attention. ${ }^{2}$ Given accumulating evidence of benefit to patients' functional abilities, we advocate for better and more equitable access to this treatment in Canada.

Cerebral palsy is a common childhood physical disability with heterogeneous manifestations that affects more than 1 in 500 children. $^{3}$ It results from an insult to the developing brain and manifests as a spectrum of neuromotor signs and symptoms, most commonly spasticity. ${ }^{3,4}$ Perinatal brain injury leads to compromise of descending inhibitory tracts that normally modulate the sensitivity of spinal motor neurons; sensorimotor reflex arcs become hyperactive, causing spasticity. Spastic cerebral palsy is graded according to the Gross Motor Function Classification System (GMFCS) from grades I to $V$, with higher grades indicating worse disability; children with grade IV-V cerebral palsy are nonambulatory. ${ }^{3,4}$ Children with grade III-V (moderate to severe) cerebral palsy reach their peak motor performance around age 4-5 years and decline in motor ability in their teenage years. ${ }^{3}$ The plateau and deterioration are in large part due to the cumulative effects of spasticity during key periods of growth.

Selective dorsal rhizotomy, a surgical procedure to section sensory rootlets in the lumbosacral spine selectively, followed by extensive rehabilitation and physiotherapy, results in improved gait for carefully selected children. ${ }^{1}$ Dorsal rhizotomy as a treatment for spasticity has existed for more than 100 years, but the procedure has evolved to be more selective and less invasive. The sensory nerve roots are exposed below the conus medullaris within the cauda equine, separated into rootlets and stimulated;

\section{KEY POINTS}

- Selective dorsal rhizotomy (SDR) is a neurosurgical treatment to reduce spasticity for children with cerebral palsy.

- There is evidence from randomized controlled trials and a recent large multicentre cohort study that SDR improves motor function and quality of life in children with cerebral palsy who are ambulatory.

- There are substantial inequities in access to SDR in Canada, which leads patients and their families to seek the procedure elsewhere, at considerable cost and potential risk.

- A recent UK policy decision to fund SDR fully for all children with moderate-ambulatory cerebral palsy highlights the need for cross-national dialogue surrounding SDR in Canada.

those sensory roots, which generate aberrant motor responses, are cut. By disrupting the sensory afferent of the aberrant reflex arc, spasticity is reduced.

Since the 1980s, SDR has been offered primarily to patients with ambulatory spastic cerebral palsy between ages 3 and 8 years. ${ }^{5}$ Offering SDR to children with ambulatory cerebral palsy is based on the rationale that these patients have the most capacity to be helped by the procedure. Selective dorsal rhizotomy is usually performed by age 8 to maintain peak motor performance and to operate before the development of worst deformity. ${ }^{3}$ Two randomized controlled trials showed SDR to be superior to physiotherapy alone in patients aged 3-8 years with ambulatory spastic cerebral palsy, ${ }^{6,7}$ and 1 randomized controlled trial failed to show any advantage. ${ }^{8} \mathrm{~A}$ subsequent meta-analysis showed significant improvement in motor scores after SDR. ${ }^{9}$ Decreased spasticity and improvement in motor scores have been shown to be maintained after 10 years of follow-up. ${ }^{10}$ Major complications of SDR are exceedingly rare. Rates of back pain, minor urologic dysfunction or minor sensory changes occur in about $10 \%$ of patients. ${ }^{11}$

The procedure has traditionally been reserved for children with ambulatory cerebral palsy. However, several experts have called for it to be considered for more severely affected, nonambulatory patients, ${ }^{12}$ who have traditionally been treated with intrathecal baclofen administration. This procedure involves the surgical implantation of an indwelling pump, which releases 
baclofen directly into the cerebrospinal fluid of the spinal cord with the goal of reducing spasticity. Although this procedure can be highly effective, the risks of hardware malfunction and, consequently, repeated operations are high. Recent evidence from case series suggests that SDR may be as effective as intrathecal baclofen treatment in carefully selected children with severe cerebral palsy. ${ }^{5,12}$

In nonambulatory cerebral palsy, however, child and caregiver goals must be considered carefully. A reduction in spasticity alone is not the goal of SDR. Rather, reduced spasticity can be seen as a tool to realize improved function and better quality of life for affected children and to facilitate care by caregivers. Not all children will benefit from reduced spasticity, as some may rely on their spasticity to assist with transfers. Children with nonambulatory cerebral palsy are often affected by dystonia as well, in which case SDR may not be advisable. The effectiveness of SDR for severely affected children is likely best assessed in terms of patient- and family-specific goals rather than gross motor measures. Ongoing efforts evaluating different outcome measures for more severely affected children are underway in an attempt to improve their quality of life.

In response to the multicentre study of SDR, ${ }^{1}$ the UK recently approved funding for SDR for all children aged 3-9 years with grade II-III cerebral palsy. The government of Ontario recently funded an SDR program at The Hospital for Sick Children and the Holland Bloorview Kids Rehabilitation Hospital. Selective dorsal rhizotomy is also performed in British Columbia, Alberta, Quebec and Nova Scotia. Access to SDR can be challenging for children living outside of these jurisdictions and for those with severe nonambulatory cerebral palsy, for which approval for surgery has not been granted.

To address inequities in access to treatments, provide a nexus for education and information, and build a registry to promote further clinical and translational research, a transnational network, the Canadian Collaborative on Best Advanced Treatments for Cerebral Palsy (CanBeAT-CP), was recently established.

In conclusion, SDR may be beneficial in children with nonambulatory cerebral palsy, but evidence is of low quality. ${ }^{10} \mathrm{How}$ ever, regardless of the child's baseline abilities or ambulatory status, the procedure should be available to all families with children with cerebral palsy to consider, not just to "reduce spasticity" but also to further the child's and caregivers' developmental and functional goals in a person-centred manner.

\section{References}

1. Summers J, Coker B, Eddy S, et al. Selective dorsal rhizotomy in ambulant children with cerebral palsy: an observational cohort study. Lancet Child Adolesc Health 2019;3:455-62.

2. Strobel M. OHIP dithers on helping girl with cerebral palsy. Toronto Sun 2017 Feb. 17. Available: https://torontosun.com/2017/02/16/help-madi-ms-wynne/ wcm/5eb53efa-b0e2-488e-ac67-191eade19f06 (accessed 2019 Oct. 15).

3. Health Quality Ontario. Lumbosacral dorsal rhizotomy for spastic cerebral palsy: a health technology assessment. Ont Health Technol Assess Ser 2017;17: $1-186$.

4. Rosenbaum PL, Walter SD, Hanna SE, et al. Prognosis for gross motor function in cerebral palsy: creation of motor development curves. JAMA 2002;288: 1357-63.

5. Peacock WJ, Arens LJ, Berman B. Cerebral palsy spasticity. Selective posterior rhizotomy. Pediatr Neurosci 1987;13:61-6.

6. Steinbok P, Reiner AM, Beauchamp R, et al. A randomized clinical trial to compare selective posterior rhizotomy plus physiotherapy with physiotherapy alone in children with spastic diplegic cerebral palsy. Dev Med Child Neurol 1997;39:178-84.

7. Wright FV, Sheli EMH, Drake JM, et al. Evaluation of selective dorsal rhizotomy for the reduction of spasticity in cerebral palsy: a randomized controlled trial. Dev Med Child Neurol 1998;40:239-47.

8. McLaughlin JF, Bjornson KF, Astley SJ, et al. Selective dorsal rhizotomy: efficacy and safety in an investigator-masked randomized clinical trial. Dev Med Child Neurol 1998;40:220-32.

9. McLaughlin J, Bjornson K, Temkin N, et al. Selective dorsal rhizotomy: metaanalysis of three randomized controlled trials. Dev Med Child Neurol 2002;44: 17-25.

10. Dudley RW, Parolin M, Gagnon B, et al. Long-term functional benefits of selective dorsal rhizotomy for spastic cerebral palsy. J Neurosurg Pediatr 2013;12: 142-50.

11. Steinbok $P$, Schrag C. Complications after selective posterior rhizotomy for spasticity in children with cerebral palsy. Pediatr Neurosurg 1998;28:300-13.

12. D'Aquino D, Moussa AA, Ammar A, et al. Selective dorsal rhizotomy for the treatment of severe spastic cerebral palsy: efficacy and therapeutic durability in GMFCS grade IV and V children. Acta Neurochir (Wien) 2018;160:811-21.

\section{Competing interests: None declared.}

This article has been peer reviewed.

Affiliations: Division of Neurosurgery (Davidson, Ibrahim), Department of Surgery and Department of Paediatrics (Fehlings, MiloManson), University of Toronto; Division of Neurosurgery (Ibrahim), The Hospital for Sick Children; Program in Neuroscience and Mental Health (Ibrahim), The Hospital for Sick Children Research Institute, University of Toronto, Toronto, Ont.

Contributors: George Ibrahim conceived the work. All of the authors drafted the manuscript and revised it critically for important intellectual content, approved the final version to be published and agreed to be accountable for all aspects of the work.

Correspondence to: George Ibrahim, george.ibrahim@sickkids.ca 